\title{
Decision Making and Information Integration in the Courts: The Setting of Bail
}

\author{
Ebbe B. Ebbesen and Vladimir J. Konečni \\ University of California, San Diego
}

\begin{abstract}
Two studies were conducted to determine how real felony court judges decide the amount of bail to set. In the first, the judges were presented with fictitious case histories containing the relevant information in a factorial design. In the second, multiple regression techniques were used to examine the impact of different kinds of information on decisions made by judges in actual bail hearings. In the simulated cases, the judges secmed to be influenced most by the degree to which the accused was tied to the area and whether or not he had a prior criminal record. However, the judges' actual bail decisions were not at all affected by these variables. Instead, their decisions were almost exclusively determined by the district attorneys' recommendations. Both the district attorneys' and the defense altorneys' actual recommendations were found to be primarily based upon the severity of the crime. These results were discussed in terms of the utility of simulation and observational research for drawing applied and theoretical conclusions.
\end{abstract}

In the American legal system, people accused of a crime are innocent until proven guilty. Proof of guilt is established only after appropriate court proceedings. A problem arises, however, because there is often a long delay between the time a person is accused of a crime and the time that his trial comes to court. How should the accused individual be treated during this delay? If he is released, he may not voluntarily appear when his trial comes to court; if guilty, he may even commit additional crimes. On the other hand, detention of the accused may result in an innocent individual being held in jail for as long as a year (Goldfarb, 1965). Bail setting evolved in the American legal system in an attempt to deal with this societal problem.

Bail hearings are usually held in public court soon after a person is indicted for a crime. The generally accepted legal purpose of these hearings is to determine the amount

The data reported in this research were collected by Holly Ingraham, David Alward, Robin Marks and Sally Quintard. Their help is greatly appreciated. Funds for statistical analyses of the data were supplied by the Center for Human Information Processing, University of California, San Diego.

Requests for reprints should be sent to Ebbe Ebbesen or Vladimir Konečni, Psychology Department, University of California, San Diego, P.O. Box 109, La Jolla, California 92037. of bail that the accused individual is to pay in order to be released from prison while awaiting trial. Discussions of guilt or innocence are generally out of order in such hearings; however, the judge, who makes the final determination of the amount of bail, does hear the defense attorney and the district attorney argue for different amounts of bail. These bail recommendations range from none (the accused is released on his own recognizance) to infinite (being held in jail without the possibility of bail). In almost all cities, the judge makes his final decision after hearing recommendations for bail from the probation department, the district attorney, and the defense attorney, as well as hearing facts to support those recommendations.

Claims have been repeatedly made that the bail system is extremely unjust. For example, in a study done in 1960 by L. Schweitzer (reported in Goldfarb, 1965), it was found that of the 114,653 people who recieved pretrial detention because they could not pay bail, only $27 \%$ were subsequently convicted and given jail sentences. In another study in Philadelphia, of 1,000 defendants who could not afford to pay bail and were therefore detained, over two thirds were either acquitted or, if convicted, were not given jail sentences. Pretrial detention averaged 33 days for these people. Goldfarb 
(1965) also notes that bail discriminates against the poor. A person who employs a bail bondsman to furnish the money necessary for his release must pay the bondsman between $5 \%$ and $10 \%$ of the amount of bail. Finally, there is some cvidence that people who are subjected to pretrial detention are more likely to be convicted and receive more severe sentences than people who can afford to pay bail, everything else being equal (Goldlarb, 1965). That such inequities exist in the bail system is understandable when one notes that no objective criteria are used to evaluate the performance of criminal justice administrators (Wildhom \& Greenwoot, 1973). If one could determine how judges actually set bail, it might be possible to make recommendations for more equitable decision rules.

One way to study the bail system is to focus on the decision processes that are used by the judges in their determination of the amount of bail to set. $\Lambda$ theoretical approach that intuitively scems to offer useful insights into a judge's decision processes is information integration theory (Anderson, Note 1). This theory is primarily concerned with the process that allows people to combine or integrate social information to form inpressions and to make decisions. Most of the laboratory research relevant to information integration theory suggests that social judgments, whether about individuals or about groups of individuals, are the result of al weighted average of the different sources of available information (Anderson, 1971; Lcon, Oden, \& Anderson, 1973). Formally, the model is described by the following equation:

$$
R=C+\frac{2 w_{i} s_{i}}{2 w_{i}}+\varepsilon
$$

where $R$ is the resultant judgment of a particular combination of information, $s_{i}$ is the value of the $i$ th type of information on the judgment dimension, and $w_{i}$ its weight relative to the other types of information used in the judgment. $C$ is an arbitrary scaling factor and $\varepsilon$ a random variable with a mean equal to zero (Anderson, 1974). In words, Equation 1 requires that each type of information receive a weight proportional to the weights of the other types of information that are available. In the case of bail setting, $s_{i}$ would be used to represent the subjective value of each type of information that judges use in their decisions, for example, the district attorney's recommendation, the severity of the crime that the person is accused of, the extent to which the person is tied to the area or appears responsible, and so on. Each $w_{\text {i }}$ would represent the weight of a given type of information relative to the other types of information that are available to the judge. The term $c$ is usually assumed, by virtue of using analysis of variance to lest the fit of the model, to be normally distributed.

The predictions that this model makes depend upon whether the scale value of a given type of information is confounded with its weight (Anderson, 1974). When the weight given to a particular type of information is independent of its value, then a parallelism prediction is made (Anderson, 1971, p. 177). That is, the difference in the final decisions between two levels of one type of information will be the same across all levels of the other types of information with which the first type is combined. In the langage of analysis of variance, parallelism is equivalent to a model with no interactions. It is also possible that the weight or relative importance of a given type of information will change as the scale value of that information changes (Oden \& Anderson, 1971). For example, Lcon et al. (1973) found that more scvere crimes were weighted more heavily than less severe crimes in a social judgment task. When the weights of one type of information are monotonically related to its scale values, Equation 1 predicts an interaction between this type of information and all others with which it is combined. The graphic form of the interaction depends upon the particular scale values and weights that are combined; however, in the language of analysis of variance, all of the interaction variance should be contained in the Linear $\times$ Linear component (Anderson, 1974).

Although it seems intuitively reasonable that judges would use some type of averaging process to put together the various types of information that they have available when setting bail, it is extremely difficult in the 
present context to determine conclusively whether the averaging interpretation is a correct one. A complete test requires that the various types of information used by the judge be combined in a full within-subjects factorial design. In real life, people are simply not accused of crimes in the experimentally appropriate manner. For this reason, the present research was not construed as providing a definitive test of the averaging model. Instead, information integration theory in general, and the averaging model in particular, were used as heuristic devices to help guide the analysis and interpretation of the results.

The severity of the methorlological diffcultics inhercnt in naturalistic research was reduced by conducting two different types of stuclies. In the first, the relevant aspects of actual bail hearings were simulated and presented to superior court judges in a full factorial design. Although this study lacked complete external validity, it was experimentally and methodologically rigorous. The fact that it was a factorial design provided the opportunity to analyze the results with reference to Equation 1. In the second study, unobtrusive obscrvation was used to collect naturalistic data. Although these data were externally valid, they were correlational rather than experimental in nature. Therefore, a direct test of Equation 1 was not possible. On the other hand, an attempt was made to analyze the results with reference to information integration by using multiple regression procedures.

\section{Experimant 1}

As noted earlier, judges are exposed to several types of information in a bail hearing. Usually these hearings are rather brief, and the total amount of information falls into a relatively small number of categories. In the San Diego felony arraignment court, where the present study was conducted, judges are given a file that indicates the crime the person is accused of and the bail recommendation of the probation department. Then they hear arguments by the district attorncy and the defense attorney, as well as their bail recommendations. The bases of the arguments raised can be classified into three major categories: the severity of the crime, the prior criminal record of the accused, and the extent to which the accused is tied to the area. If one includes the district attorney's recommendation and the defense attorney's recommendation, the average judge is exposed to at least five major types of information, each of which can vary in value. ${ }^{1}$

The first experiment was designed to provide evidence about both the importance of these different types of information in the bail-setting decision and the integration rule used to put these different types of information together. Felony court judges in San Diego were presented with simulated versions of the information normally presented to the judges in bail hearings. Because the judges were only willing to spend a small amount of time on the project, the usual strategy of running each subject through the entire factorial design was not possible. Instead, each judge was exposed to a random sample of treatment combinations. In an additional attempt to reduce the amount of time of each judge's participation, one type of information already known to be important in bail setting, the severity of the crime, was eliminated (Goldfarb, 1965). In this way, a simulation consisting of a complete four-factor design was carried out; there were two levels of prior record, two levels of local ties, three levels of defense attorney recommendation, and three levels of district attorney recommendation.

\section{Method}

\section{Subjects}

Subjects were 18 San Dicgo municipal and superior court judges who had been involved in bail hearings prior to the experiment and who agreed to participate in the study. The judges were approached by a male college student who said that he was conducting a survey for a social psychology class. Hc told the judge that the survey was concerned with bail setting and asked if the judge would help by giving a few minutes of his time. Eighteen of the 22 judges contacted agreed to participate.

1. The probation department's recommendation was ignored in this study partly because it was rarely mentioned in open court, but primarily because in the few cases it was mentioned the district attorney's recommendation was identical to it. 


\section{Procedure}

Each judge was given eight different "case records" designed to simulate the type of information typically available in bail hearings. The judges were told that these cases were selected from the trial archives in San Diego and that they were all concerned with the crime of robbery. They were further told that other factors such as age and sex of the accused would not vary in these cases. Each case record was presented on a scparate sheet of paper. The judge was asked to indicate, as best as he could, the actual amount of bail that he would set assuming that the case record was information that he had received in a bail hearing. All judges accepted this task as reasonable and carefully analyzed each case before giving their recommendations.

Each of the case records presented a list of descriptive information, which was constant across all records. The age of the accused was always set between 21 and 25 years, since $60 \%$ of the fulony cases in San Dicgo involve people in this age range. He was described as an unmarried male Caucasian who had been charged with robbery. As with almost all such cases, the plea was "not guilty." In an attempt to convince the judges further that these were records of actual cases, details of the robbery were varied slightly over the eight cases: two TV sets were taken from an appliance store, cash and clothing from a boutique, cash and tires from a gas station, cash and liquor from a liquor store, cash and merchandise from a department store, cash from a restaurant, cash from a Specdy Mart, cash from a bus depot, and gems from a jewelry store. The value of the stolen property was always set between $\$ 850$ and $\$ 950$.

District attorney recommendation. In 30 of the 106 actual cases reported in Experiment 2, the accused was charged with robbery. The mean bail recommended by the district attorneys in these robbery cases was $\$ 2,850$. The range was $\$ 500$ to $\$ 10,000$. Three levels of bail were chosen in this experiment in an attempt to simulate the types of bail usually recommended by the district attorneys for robbery charges. The low level ranged from $\$ 1,500$ to $\$ 1,700$, the moderate Ievel from $\$ 2,000$ to $\$ 2,500$, and the high level from $\$ 5,000$ to $\$ 7,500$. The low level was restricted by the requirement that it could never be less than the defense attorney's highest recommendation, because in all of the actual cases studied, the defense attorney's recommendation was either the same as or less than the district altorney's recommendation.

Defense attorney recommendation. In the same 30 robbery cases mentioned above, the mean defense attorney recommendation was $\$ 747$. The range was $\$ 0$ to $\$ 5,000$. The three levels of defense attorney recommendation were chosen to simulate these observations without exceding the lowest district attorney recommendation. The low level was always $\$ 0$ (i.e., to release the accused on his own recognizance), the moderate level ranged between $\$ 500$ and $\$ 600$, and the high between $\$ 1,000$ and $\$ 1,200$.
Since the defense attorneys recommended $\$ 0$ bail in $56 \%$ of the actual robbery cases studied, $\$ 500$ in $22 \%$, and $\$ 1,000$ in $16 \%$, these values represented those most often used in actual cases.

Prior record. In actual bail hearings, district attorneys usually support their recommendations with information about the prior criminal record of the accused. To simulate this aspect of the bail hearing, the case records included two levels of prior record, both of them described in conjunction with the district attorney's recommendation. The accused was said either to have no prior record or to have a prior felony record and to be on probation at the time of the bail hearing. These two levels simulated $93 \%$ of the actual robbery cases studied.

Local ties. In an attempt to justify his lower recommendation, the deicnse attorney usually presents the accused as a responsible person. He does this most often by describing whether the accused lives in the local area, whether he is married and has children, whether he is employed and for how long, and whether he has relatives who live in the area. Two extremes of this type of information were used in the present study. To simulate strong local ties, the defense attorney noted that the accused had lived in San Diego for 4 to 6 years, was cmployed, and that his family was also living in San Diego. Weak tics were simulated by noting that the accused had been living in San Diego for only 1 to 2 months, was uncmployed, and that his family lived in northern California.

\section{Design}

These independent variables were presented to the 18 judges in such a way that the resultant judgments yiclded a $3 \times 3 \times 2 \times 2$ factorial design with four observations per cell. Individual judges were randomly assigned to a group of eight case records selected from the entire factorial matrix in such a way that no judge was exposed to the same level of any independent variables more than twice.

\section{Results and Discussion}

The primary purpose of this experiment was to determine how judges integrate the four types of information to arrive at a bail recommendation. Table 1 contains the mean bail recommended by the judges for each condition in the full factorial design. An analysis of variance was performed on the means in Table 1 . The results of this analysis are presented in Table 2. As can be seen, three of the main effects were significant, but none of the two-way or higher order interactions were.

Examination of the appropriate means in Table 1 shows that the average recommendation was higher when the accused 
TABLE 1

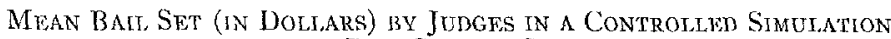
of time BAIt-Setring StTUATION

\begin{tabular}{|c|c|c|c|c|c|c|c|}
\hline \multirow{2}{*}{$\begin{array}{l}\text { District } \\
\text { attorney rec- } \\
\text { ommendation }\end{array}$} & \multirow[b]{2}{*}{$\begin{array}{l}\text { Prior } \\
\text { record }\end{array}$} & & \multicolumn{3}{|c|}{ Defense attorne } & \multicolumn{2}{|c|}{$\$ 1,100$} \\
\hline & & Strong & Weak & $\frac{\$ 550}{\text { Strength of local ties }}$ & & Strong & Weak \\
\hline \multirow{2}{*}{$\$ 1,600$} & No & 687 & 2,775 & 937 & 1,550 & 2,000 & 1,550 \\
\hline & Yes & 2,500 & 2,125 & 1,312 & 1,900 & 2,550 & 2,500 \\
\hline \multirow{2}{*}{$\$ 2,250$} & No & 1,625 & 2,375 & 750 & 2,312 & 1,750 & 2,625 \\
\hline & Yes & 1,250 & 2,375 & 1,387 & 3,000 & 1,750 & 2,875 \\
\hline \multirow{2}{*}{$\$ 6,250$} & No & 1,125 & 3,250 & 2,125 & 2,875 & 1,550 & 3,300 \\
\hline & Yes & 2,750 & 5,687 & 3,125 & 3,375 & 1,600 & 4,250 \\
\hline
\end{tabular}

was weakly tied to the area than when he was strongly lied, and it was higher for an accused who had a prior record than one who had none, and that it increased as the district attorney's recommendation increased. Interestingly enough, the defense attorney's recommendation had no significant effect on the bail that the judges finally set.

The present results can also be analyzed with reference to information integration theory. The lack of significant interactions in the analysis of variance can be understood by assuming either that the judges added the subjective values of the local ties, prior record, and district attorney information, or that they averaged them. Although the present results do not provide a quantitative way to determine which of these models yields the more reasonable description of the judges' integration scheme, there are several reasons to prefer the averaging interpretation over the adding one. The logic behind these arguments rests on the fact that the district attorney recommendations and the judges' bail recommendations were on the same physical scale, namely, amount of money. It seems justifiable to assume that the subjective value of a given amount of bail was the same on both scales.

If the above reasoning is accepted, then two aspects of the present results are better understood in terms of an averaging model (with unconfounded weights) rather than an adding model. The first is that the judges' overall mean bail $(\$ 2,279)$ was less than the overall mean district attorney recommendation $(\$ 3,367)$ but greater than the average defense attorney recommendation $(\$ 550)$. A simple adding model would expect the addition of information about prior record and local ties to cause the judges' recommendations to be higher than the district attorneys' recommendations. If the scaling assumptions are true, the judges should have added more money to the district attorney's recommendations the longer the accused's prior record or the weaker his ties to the area.

TABILE 2

Analysis ol: Variancli of Mean BaIL SET BY JUdGeS IN TIEE Simulation

\begin{tabular}{lrrc} 
Source & df & \multicolumn{1}{c}{ MS } & \multicolumn{1}{c}{$F$} \\
\hline Prior record (A) & 1 & 123.67 & $5.91^{*}$ \\
Local ties (B) & 1 & 468.08 & $22.38^{* *}$ \\
Defense attorney (C) & 2 & 18.90 & $<1$ \\
District attorney (D) & 2 & 147.45 & $7.05^{* *}$ \\
$\mathrm{~A} \times \mathrm{B}$ & 1 & .71 & $<1$ \\
$\mathrm{~A} \times \mathrm{C}$ & 2 & 1.88 & $<1$ \\
$\mathrm{~A} \times \mathrm{D}$ & 2 & 25.29 & 1.21 \\
$\mathrm{~B} \times \mathrm{C}$ & 2 & 14.73 & $<1$ \\
$\mathrm{~B} \times \mathrm{D}$ & 2 & 46.36 & 2.22 \\
$\mathrm{C} \times \mathrm{D}$ & 4 & 14.29 & $<1$ \\
$\mathrm{~A} \times \mathrm{B} \times \mathrm{C}$ & 2 & 9.88 & $<1$ \\
$\mathrm{~A} \times \mathrm{B} \times \mathrm{D}$ & 2 & 14.89 & $<1$ \\
$\mathrm{~A} \times \mathrm{C} \times \mathrm{D}$ & 4 & 17.51 & $<1$ \\
$\mathrm{~B} \times \mathrm{C} \times \mathrm{D}$ & 4 & 28.99 & 1.37 \\
$\mathrm{~A} \times \mathrm{B} \times \mathrm{C} \times \mathrm{D}$ & 4 & 16.10 & $<1$ \\
Error & 108 & 20.92 &
\end{tabular}

a These values should be multiplied by $10^{\circ}$ to obtain the true mean squares.

$* 2<.05$. 
The second aspect of the results that should be considered is the relationship between the amount of the district attorneys' recommendations and the amount of bail. Given equivalent subjective values on these two scales, the relationship should be a linear function. A simple adding model would expect the slope of this function to be 1 , since, as already noted, the addition of the local ties and prior record information to the decision would merely raise or lower the mean (or $y$ intercept) of the judges' decisions. Given the same scaling assumptions, an averaging interpretation implies that the inclusion of this extra information would reduce the relative importance or weight of the district attorneys' recommendations. Such a change would reduce the slope of the above linear function. The mean amounts of bail set by the judges as a function of the district attorney's recommendation were $\$ 1,916$, $\$ 2,006$, and $\$ 2,918$. When plotled against the amount of the district attorney recommendation, the resulting curve was a linear function with a slope of $.22 \quad(F<1$ for the residual variance not accounted for by the linear contrast).

It should be emphasized that the above analyses do not prove that the judges were actually averaging the various types of information to arrive at their bail decisions. They do show, however, that an equal-weight, averaging interpretation is consistent with the pattern of results and that other intuitively reasonable integration rules that would have predicted significant interactions (e.g., multiplicative combinations or averaging with confounded weights) are not tenable.

The proportion of variance that each factor accounted for in the present research is of considerable applied interest because the levels of the factors simulated the most frequently occurring levels in actual bail hearings. Proportion of variance therefore should provide information about the relative importance of these variables (given the studied levels) in the actual decision-making process. The strength of the local tics accounted for most of the between-cell variation, the district attorney's recommendation the next most, and prior record the least. It should be stressed that these results repre- sent a reasonable decision-making scheme on the part of the judges, given the "innocent until proven guilty" philosophy of our legal system. Their decisions required people who had little reason to remain in the area while awaiting trial (weak ties) to post more bail than people who had many reasons for remaining in the area (strong ties). According to the Vera Foundation (Goldfarb, 1965) this strategy of bail setting has met with great success in New York City and presently appears to form the basis of most bail decisions made in the New York City felony courts. The present results imply that the San Diego felony court judges also operate according to the Vera Foundation rules.

\section{EXPARIMENT 2}

Although the use of real judges as subjects in the previous simulation increased the external validity of the study, it did not eliminate all of the objections that might be raised to conclusions drawn from it. The judges were, after all, quite aware that they were being tested by a college student who was interested in the bail-setting process. They may have attempted to present thenselves as unbiased decision makers by responding: more to the local ties variable than they normally would.

In addition, some of the judges reported that certain combinations of the four factors would never occur in real bail hearings. If such reactions are important, certain cells in the full factorial may have produced unrepresentative means, thereby greatly reducing the external validity of the study. One strategy for counteracting these difficulties with external validity was to obtain information from actual bail hearings. It should be noted that this strategy has rarely, if ever, been employed in research whose aim has been to study information integration. Most of these studies have been content to rely on the findings from contrived and highly controlled laboratory situations. Comparisons of naturalistic data with the previous results therefore offer the opportunity to assess both the applied and the theoretical importance of the previous findings. (Which factors influence the judges' decisions and how are they integrated?) 
In the present study, observers sat in actual bail hearings and recorded the information presented to the presiding judges, as well as the amount of bail that they set. These data were then analyzed using multiple regression procedures. The use of multiple regression enabled us to determine the rela tive predictive utility of the same independent variables that wore examined experimentally in the previous study. Would the same factors again prove to have predictive value?

Unfortunately, the traditional information integration models could not be directly used to aid the interpretation and analyses of these naturalistic data. Integration models generally assume that the scale values of the various types of information presented to the subjects are orthogonal or uncorrelated. As already noted, such is rarely the case in real bail hearings. However, it is possible to develop new integration models that have the same general properties as those which assume orthogonal combinations of factors but also allow for correlations between the independent variables. These new models are useful not only because they allow comparisons to information integration theory, but also (and primarily) because they suggest different ways of analyzing the existing naturalistic data.

One model that has properties similar to those of adding and averaging (with orthogonal weights) is

$$
R=b_{0}+\Sigma b_{i} X_{i}+\varepsilon,
$$

where $R$ is the judge's final decision, $b_{o}$ is an additive constant (similar to $C$ in Equation 1), the $b_{i}$ are weights applied to each $X_{i}$ factor, and $\varepsilon$ represents an additive random variable with a mean of zero. If the $b_{i}$ were restricted to sum to 1.0 , then the model would be an averaging one. The $X_{i}$ represent the values of the different types of information on which the judges base their bail-setting decisions.

Equation 2 is formally a multiple regression model and therefore can be quantitatively tested using multiple regression procedures. The virtue of multiple regression procedures in the present context is that they allow for correlations among the $X_{i}$. However, multiple regression usually assumes that the physical values of each $X_{i}$ fall on an interval scale. (Information integration uses functional measurement to establish the interval nature of the scale.) Furthermore, Equation 2 necessarily requires that each $b_{i}$ weight be independent of the specific value of its associated $X_{i}$. This means that Equation 2 is best thought of as a weighted adding model because it does not allow for interactions between the independent variables.

On the other hand, the fact that the weights are independent of the values and that no interactions are included in the model makes Equation 2 similar (but not identical) to an averaging model in which the weights are independent of the scale values. Fortunately, it is possible to devise a model that contains interaction terms and thus allows for the confounding of weights and scale values. The Linear $\times$ Linear interactions that would be predicted by a weighted averaging model when there is a monotonic confounding between the weight and scale values of one type of information can be represented by twoway interactions between that type of information and all others (Cohen, 1968). Formally, this new model would look as follows:

$$
R=b_{o}+\Sigma b_{i} X_{i}+\Sigma \Sigma b_{i j}\left(X_{i} X_{j}\right)+\varepsilon,
$$

where the $X_{i} X_{j}$ represent the multiplicative (or Linear $x$ Linear) interactions of all pairs of the $X_{t}$ factors. Three-way and other higher order interactions would also be required if weights and scalc values were confounded for more than one type of information. If the interaction terms do not account for a significant portion of the variance in $R$ over and above the main effects of the $X_{i}$, then it is possible to argue but not prove that the $X_{i}$ are producing parallel effects.

\section{Method}

\section{Subjects}

Only five of the judges who served in the first experiment sat on the bench in bail hearings during the conduct of the study. Therefore, the data in this experiment were obtained by unobtrusively observing these five judges in actual bail hearings in the felony court.

\section{Procedure}

Trained observers sat in the courtroom with spccially prepared data shects. For each case, they 
recorded the following information: the sex of the accused, his/her approximate age, the type of crime(s) presumed to have been committed, the plea of the accused (guilty or not), whether a defense attorney was present, the amount of bail that the defense attorney recommended, the amount of bail that the district attorney recommended, the extent of the accused's priol criminal record, whether the accused was employed, whether the accused lived in the San Diego area, and for how long, whether the accused had relatives living in the San Diego area, and the amount of bail finally set by the presiding judge. In about $35 \%$ of the cases that were heard, some major portion of this information was not brought out in the hearing. Since $96 \%$ of the accused individuals were males between the ages of 18 and 30 , age and sex were ignored in the final analyses. Because a guilty plea was entered in only one case, this variable was also ignored.

Reliability of the data-recording method was obtained by having two observers independently and simultancously collect data for 23 cases. Their data recolds were identical in all respects, indicating perfect reliability.

Definition of levels of the factors. The final analysis was conducted using five independent variables to predict the judges' decisions: severity of the crime, severity of the prior record of the accused, strength of the local ties of the accused, district attorney's recommendation, and defense attorney's recommendation.

Severity of the crime. $\Lambda$ total of 14 different crime categories were initially identified. These were homicide, kidnapping, lape, assault, armed robbery, possession of a deadly weapon, sale of drugs, robbery, burglary, theft, forgery, possession of drugs, scxual perversion, and AWOL. The fourteen crimes were collapsed into the following seven categories: (a) homicide, (b) violent crimes not resulting in death (kidnapping, rape, and assault), (c) crimes with the potential of violence or death (armed robbery, possession of a deadly weapon), (d) nonviolent but major crimes with specific victims (sale of drugs, robbery), (e) nonviolent minor crimes with specific victims (burglary, theft), (i) nonviolent crimes with nonspecific victims (forgery, sexual perversion), (g) victimless crimes (possession of drugs, AWOL). These seven categories were used to specily the severity of the crime. It should be noted that the ordering described here matches that established in previous judgmental research (c.g., Coombs, 1967; Leon et al., 1973).

prior record. Four categorics of prior criminal record on the part of the accused could be estab. lished. These were: none, a minor record consisting only of traffic violations, a moderate prior record consisting of no more than one felony conviction of a nonviolent crime, or a severe prior record consisting of more than one felony conviction or one violent crime felony conviction. In ilmost all of the severe prior record cases the accused was also on parolc.

Local ties. Three catcgorics of local ties were defined. The accused was said to have weak ties if he had not lived in the San Diego area for more than a month. The accused was said to have moderate ties if he had lived in the area for over a year, but was unemployed at the time of arrest. Strong ties meant that the accused lived in the area for over a year, was steadily employed, and also had relatives living in the area.

Defense attomey recommendation. The actual monetary recommendation made by the defense attorney was used as a predictor. The range of values was from $\$ 0$ to $\$ 25,000$ (in one murder case).

District attorney recommendation. The actual monetary recommendation made by the district attorncy was also used as a predictor. The range of values was from $\$ 0$ to $\$ 100,000$.

Actual bail set. In all of the cases studied, the judge announced the bail that was to be set so that it could be recorded by the court stenographer. This oral statement was used as the actual bail set.

\section{Results and Discussion}

There were two purposes to this study. The first was to determine whether the same factors that were important in the judges' simulated decisions would prove important in their actual bail decisions. The second was to determine whether or not the same integration model used to explain the results from the full factorial design could be generalized to actual bail hearings. Multiple regression procedures were used in an attempt to accomplish both of these aims.

A few words are in order concerning the use of multiple regression in the context of a theory whose methods generally assume orthogonal factorial designs. Some users of multiple regression methods simply test the significance of the sum of squares accounted for by the multiple regression model. If this test is significant, they conclude that the model is useful. Although this strategy has merit in some applications, it is not adequate for the concerns of the research reported here. As Birnbaum (1973) has shown, a strictly additive multiple regression model can account for a significant and large proportion of sum of squares even though the data were generated from a multiplying model, and vice versa. A partial solution to this problem is available, however. It can be appreciated by analogy to analysis of variance. In the use of analysis of variance to determine whether the weights and scale values are confounded in an averaging task, the significance of the interactions are 
TABLE 3

Multiple Rrgiession Analyses of Judges' Actual Batl Decisions (WITI and Witiout MuRder Casles)

\begin{tabular}{|c|c|c|c|c|c|}
\hline \multirow[b]{2}{*}{ Source } & \multicolumn{3}{|c|}{ A: With murders } & \multicolumn{2}{|c|}{ B: Without murders } \\
\hline & $d f$ & $M S$ & $F$ & $M S$ & $F$ \\
\hline Regression (all; Eq. 3) & 15 & 117.72 & $29.73^{* * *}$ & 128.65 & $155.77^{* * *}$ \\
\hline Regression (main eflects only; Iq. 2) & 5 & 338.97 & $85.60^{* * * *}$ & 377.50 & $319.90^{* * *}$ \\
\hline Residual & 10 & 7.10 & 1.79 & 4.23 & $5.12^{* * *}$ \\
\hline Crime $(\Lambda)$ & 1 & 1.57 & $<1$ & 3.52 & $4.26^{*}$ \\
\hline Prior record (B) & 1 & .68 & $<1$ & 1.33 & 1.61 \\
\hline Local ties (C) & 1 & 4.98 & 1.25 & .02 & $<1$ \\
\hline Defense attorney (I)) & 1 & 49.72 & $12.56^{* *}$ & 19.52 & $23.63^{* * *}$ \\
\hline District attorney (C) & 1 & 312.76 & $78.08^{* * *}$ & 432.67 & $523.81 * * *$ \\
\hline$\Lambda \times 13$ & 1 & .44 & $<1$ & 1.20 & 1.45 \\
\hline$A \times C$ & 1 & .56 & $<1$ & 2.30 & 2.78 \\
\hline$A \times D$ & 1 & .12 & $<1$ & 8.75 & $10.59^{*}$ \\
\hline$A \times \mathrm{F}$ & 1 & 1.22 & $<1$ & .28 & $<1$ \\
\hline$B \times C$ & 1. & .55 & $<1$ & .24 & $<1$ \\
\hline $\mathrm{B} \times \mathrm{D}$ & 1 & .99 & $<1$ & .01 & $<1$ \\
\hline $\mathrm{B} \times \mathrm{E}$ & 1 & .86 & $<1$ & 1.81 & 2.19 \\
\hline$C \times 1)$ & 1 & .03 & $<1$ & .03 & $<1$ \\
\hline $\mathrm{C} \times \mathrm{E}$ & 1 & .03 & $<1$ & .08 & $<1$ \\
\hline 1) $\times \mathrm{E}$ & 1 & .45 & $<1$ & 12.46 & $15,08^{* * *}$ \\
\hline Error & 90 & 3.96 & & $.83^{n}$ & \\
\hline
\end{tabular}

a Degreas of freedom for this MS were 86.

$\because p<.05$.

$* 0,0<1.001$

examined rather than the overall betweenconditions $F$. If the interactions are significant, then one cannot conclude that the weights and scale values are orthogonal. Another way of speaking about this test in language compatible with multiple regression is to ask whether or not the interactions account for any additional between-conditions sum of squares, over and above that predicted by the main effects. The identical test is available in multiple regression (cf. Cohen, 1968; Overall \& Spiegel, 1969). In the present case, the test is accomplished by determining whether or not Equation 3 (which includes interaction terms) accounts for a significant amount of additional variance over and above that which Equation 2 can account for. ${ }^{2}$

2 Cohen (1968) has shown how nonlinear interactions can be included in the model as well as lineac oncs. The most elegant test of Equation 3 as a derivation of averaging would be to show that all of the interaction variance was predicted by the simple Linear $\times$ Linear component. Unfortunately, such a test requires a great number of data points to insure singularity of the data matrix. The present data base was not large enough to accomplish this test.
Table 3 presents a breakdown of the sums of squares that Equations 2 and 3 were able to account for. The sums of squares for the main effects of each type of information as well as all of the two-way interactions were obtained using Overall and Spiegel's Method 2 (1969). Briefly, since the independent variables were correlated, some of the variance that can be accounted for by one factor can also be accounted for by another factor. Therefore, each main effect in Table 3 represents the additional, or noncommon, sum of squares that it contributes to Equation 2. Each interaction effect represents the additional, or noncommon, sum of squares that it contributes to Equation 3.

of initial interest is the rather good predictability of the data. Panel A of Table 3 presents the results of the multiple regression analysis of all of the data (including the murder cases). Equation 2, with five independent variables, accounted for $79.9 \%$ of the variance in the judges' bail decisions; Equation 3, with 15 variables, accounted for $83.2 \%$ of the variance. When treated in isolation from the other variables, each of the five factors predicted a significant portion of the 
variance in the bail that judges actually set. The weakest single predictor was prior record, $F(1,104)=7.39, p<.01$, whereas the strongest was the district attorncy's recommendation, $F(1,104)=411.17, p<.01$. Since the independent variables were correlated with one another, some of these factors may have predicted bail by virtue of correlations with other predictors. This possibility was assessed by examining (in Table 3 ) the noncommon sum of squares that each of the five variables added to the overall multiple regression. As can be scen, only the defense and district attorneys' recommendations improved the predictions. It is reasonable to assume, therefore, that the other three factors were associated with the amount of bail that was set by virtue of being correlated with the defense and district attorneys' recommendations. Since the judges were presented with all five types of information in the bail hearings, it is also safe to conclude from these results that scverity of the crime, prior record, and local ties had no influence that can not be explained more simply by attending to the attorneys' recommendations.

The fact that the additional sum-of-squares accounted for by all of the two-way interactions (Residual in Table 3 ) was not significant implics that Equation 3 does not yield a more useful description of these results than Equation 2. The simple model without interactions provides an equally good explanation of the judges' decision processes.

One problem with interpreting the results in panel $\mathrm{A}$ is that they were based upon data which included four homicide cases. Bailsetting procedures for homicide cases may not be representative of the way in which bail is set for lesser crimes. For example, even though most murders are committed by people who live in the area in which the murder was committed and who have no prior criminal record (see Table 5), very large bail bonds are nevertheless usually recommended by the district attorney (c.g., around $\$ 100,000)$. Although such outcomes can be taken into account by multiple regression, they still could distort the role that local ties, prior record, and severity of crime play in determining a judge's bail decision in the large majority of bail hearings that do not involve murder. Therefore, the data were reanalyzed without the four murder cases. The results of these analyses are presented in panel B of Table 3. As can be seen, several differences emerged. When the murder cases were eliminated, severity of crime accounted for a significant portion of additional variance. Furthermore, in these data Equation 3 accounted for a significant amount of additional variance over and above that explained by Equation 2, and both Equations 2 and 3 accounted for a greater portion of the total variance ( $94.3 \%$ and $95.6 \%$, respectively).

The presence of two significant interactions in the data without the murclers (District Attorney $\times$ Deiense Attorney; Severity of Crime $\times$ Defense Attorney) raises a major interpretative problem. If we assume that the $X_{i}$ values used in the above analyses fell on an interval scale, then the significant interactions may be taken as direct evidence against the general utility of liguation 2, and as indirect evidence against the external validity of the orthogonal weights averaging interpretation given for the simulation study. Had the judges been combining the various factors according to this simple averaging rule, then the interactions would not have been significant.

Several alternative interpretations can be given for the pattern of results that was obtained. One might conclude that the judges were combining the various types of information according to some complex interactive rule not easily specified in algebraic form. Alternatively, the judges might still be averaging the information, but in such a way that the weight of one or more of the factors was confounded with its scale values. This latter interpretation has intuitive appeal for several reasons. First, the mean bail bond $(\$ 2,162$ without murders) again fell between the district attorneys' $(\$ 2,820)$ and the defense attorneys' (\$583) mean rccommendations. Second, it is possible to explain both interactions by assuming that the judges confounded the weight of the defense attorneys' recommendation with its size. While the nature of the data does not allow a direct test of this explanation, an intuitively con- 
vincing argument can be made in its favor. One might generally expect a defense attorney to recommend a very low bail unless there were some noteworthy additional factors that would suggest that a higher bail bond be imposed. A judge might therefore give greater weight to higher bail recommendations on the part of the defense attorney. As noted in the introduction, such a monotonic confounding between the weight and scale values of one factor should, according to Equation 1, produce significant Linear $\times$ Linear interactions with all other significant factors.

Additional information is available in the data that is important for the above interpretation of the results. From the previous analysis, we know that judges seemed to rely chiefly on the recommendations of the district attorney and the defense attorney in setting bail and that prior record and local ties played no additional role in judges' decisions. Severity of the crime played a minor role, however, when the homicide cases were ignored. The fact that severity of the crime, prior record, and local ties play a limited role in determining a judge's bail decision seems to fly in the face of both intuition and previous results (Goldfarb, 1965). A possible explanation for this finding may be that district attorneys and/or defense attorneys take these variables into account when they recommend bail, and that judges know this to be the case. In addition to explaining why other variables contributed so little, this argument would provide further insights into how judges make their final decision.

Evidence relevant to this issue can be obtained by performing regression analyses directly on the district attorneys' and the defense attorneys' recommendations. If the district and defense attorneys do take these other variables into account, a major portion of the variance in the attorneys' recommendations should be accounted for by such factors. Table 4 presents the results of the appropriate regression analyses for the data including and excluding the murder cases. Identical analyses were also performed on the judges' decision for comparative purposes. When murders were included (panel A),

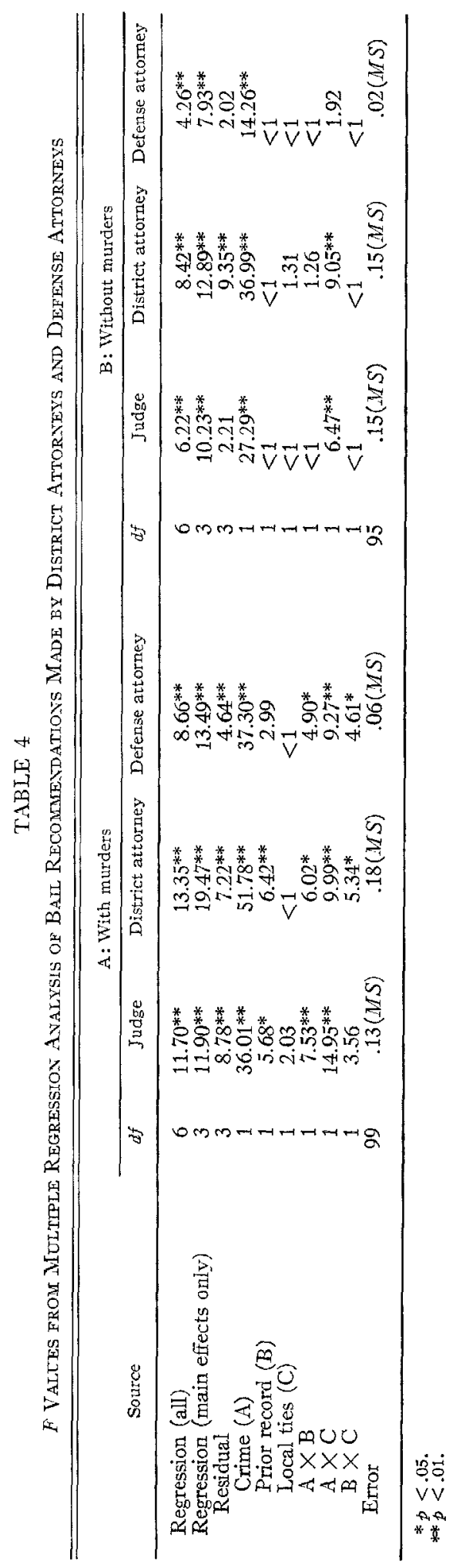


severity of crime and prior record accounted for major portions of the variance in the recommendations made by district attorneys. There was still no main effect of local ties, however. The pattern of results was similar for the defense attorneys' recommendations, the onc exception being no effect of prior record. All three two-way interactions were significant for both the district attorney and the defense attorney.

When the four murder cases were excluded (panel B in Table 4), prior record no longer had a main effect, and two of the interactions Crime $\times$ Prior Record and Prior Record $\times$ Local Ties, disappeared. Thus, for the bail hearings without homicides, only severity of crime had a main effect on the district and defonse attorneys' recommendations. Furthermore, the interaction between severity of crime and local ties was only significant for the district attorneys' recommendations.

Taken as a whole, these results suggest that factors such as severity of crime and local ties do indirectly affect the amount of bail that is finally set by directly influencing the district attorneys' and the defense attorneys' recommendations, which in turn influence the judges' final decisions.

The weak effect of severity of the crime found for the judges' decisions may indeed have been caused by a belief, based on experience, that one or both of the attorneys take severity of crime into account in their recommendations. In other words, information about the severity of crime may be considered highly redundant with either the defense or the district attorneys' recommendations. If, as the results in Table 3 suggest, the judge relied chiefly on the district attorney for his final decisions, the redundancy might primarily affect the weight of the defense attorneys' recommendations. Since the defense attorneys almost always recommend very low or no bail in the less severe cases, the judge could effectively ignore a defense attorney's recommendation in such cases. With more severe crimes, however, the defense attorneys' recommendations might take on greater relative importance in the overall decision. It should be recalled that this same explanation can account for the two interactions found in the judges' decisions.

An additional theoretical point can be made concerning the way in which the district attorneys decided on their recommendations: As with the judges, we can ask how they combined severity of crime, prior record, and local ties. The pattern of results for the district attorneys, that is, the interaction between severity of crime and local ties, is inconsistent with the orthogonal weights-averaging model originally proposed for the judges. In an attempt to provide an explanation for these effects, the mean bail recommended by the district attorneys as a function of the strength of local ties and the severity of the crime (presented in Table 5) were computed. As can be seen, the slope of the relations between severity of crime and bail recommendation was steeper when the local ties were strong or moderate than when they were weak. That is, the district attorneys recommended more bail in four out of five crime

TAISLE 5

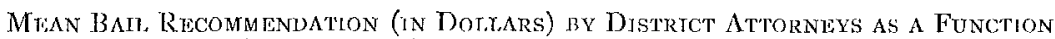
on Severity of Crime and Setringth of 1.ocal. Thes

\begin{tabular}{|c|c|c|c|c|c|c|c|}
\hline \multirow{2}{*}{$\begin{array}{l}\text { Strength of } \\
\text { local ties }\end{array}$} & \multirow{2}{*}{$---\frac{}{a}$} & \multicolumn{5}{|c|}{ Severity of crime calegoryn } & \multirow[b]{2}{*}{$\mathrm{g}$} \\
\hline & & b & c & 1 & c & $\mathrm{f}$ & \\
\hline Strong & $\begin{array}{c}81,250 \\
(4)\end{array}$ & $\begin{array}{c}10,250 \\
(4)\end{array}$ & $\begin{array}{c}7,916 \\
(6)\end{array}$ & $\begin{array}{c}1,796 \\
(16)\end{array}$ & $\begin{array}{c}5,166 \\
\text { (3) }\end{array}$ & $\begin{array}{c}1,820 \\
(5)\end{array}$ & $\begin{array}{c}352 \\
(14)\end{array}$ \\
\hline Moderate & $\overline{(0)}$ & $(0)$ & $\begin{array}{c}7,62.5 \\
(4)\end{array}$ & $\begin{array}{c}2,423 \\
(13)\end{array}$ & $\begin{array}{c}2,2.50 \\
(6)\end{array}$ & $\begin{array}{c}5,000 \\
\text { (1) }\end{array}$ & $\begin{array}{l}625 \\
(8)\end{array}$ \\
\hline Weak & $(0)$ & $(0)$ & $\begin{array}{c}3,750 \\
(2)\end{array}$ & $\begin{array}{c}1,500 \\
(5)\end{array}$ & $\begin{array}{c}1,500 \\
(2)\end{array}$ & $\begin{array}{l}667 \\
(3)\end{array}$ & $\begin{array}{c}1,100 \\
(10)\end{array}$ \\
\hline
\end{tabular}

Note. Number in parentheses represent cell $\mathrm{ns}$.

a See text (peragraph headed Severity of crime in the Procedue section of Trperiment 2) for explanation of the categories. 
categories when the ties were strong or moderate than when they were weak. Thus, being tied to the area was actually detrimental to the defendant in the more severe crime categories. If we assume that strong and moderate ties were generally ignored by district attorneys, such behavior could be understood in terms of a different averaging model, one in which the weight and scale value of the local ties variable was confounded. If strong and moderate local ties received a small or nearzero weight, then the severity of the crime would receive a large relative wight. With weak local ties, an increase in its weight would decrease the relative weight of the severity of the crime and thereby lower the slope. Although this is but one explanation of the district attorneys' behavior, it does make sense to assume that the district attorney would ignore the local ties variable when it indicated that the defendant was fairly strongly tied to the area. What is interesting is the strange behavior such a decision strategy can produce.

\section{COMPARtson of EXPERIMENTS 1 AND 2}

The fact that there were several important differences between the results of the simulation experiment and the naturalistic study suggests that further comparisons between the two sets of data are in order. The two major differences between the results were (a) the presence of an interaction between the district attorney's recommendation and the defense attorney's recommendation in the naturalistic study but not in the simulation study and (b) the relative importance of the studied variables in determining the amount of bail finally set.

Several alternative explanations are available for the presence of the District Attorney $\times$ Defense Attorney interaction in the naturalistic data as well as the lack of interaction in the simulation. With regard to the simulation, it is quite plausible that no interaction was found because the main effect of the defense attorney was not significant in that study. If our claim that small defense attorney recommendations are generally ignored by the judges is correct, the range of defense attorney recommendations presented in the simulation may have been given exactly that, a zero or near-zero weight by the judges. Alternatively, the difference between the studies may have arisen because of inherent difficulties with the use of multiple regression as an analytic tool. The values used for the interaction in the naturalistic study may have been correlated with a variable not included in our analysis but one that the judges used in their final decisions. This explanation seems unlikely, however, since no other potentially important variables could be found in the actual bail hearings.

An attempt can be made to test the rangeof-values explanation by studying the relationships between the observed variables only for those cases in which the level of the independent variables exactly matched those used in the simulation procedures. Furthermore, once these cases are selected, it is possible to analyze them using dummy-variable multiple regression, a technique that is identical to the least-squares analysis of variance (Applebaum \& Cramer, 1974; Cohen, 1968; Overall \& Spiegel, 1969; Wolf \& Cartwright, 1974).

A total of 63 cases were selected from all of those available. Only those cases in which the amount of bail recommended by the district and defense attorneys, the extent of prior record, and the type of local ties of the accused exactly matched the levels of these variables used in the simulation were analyzed. Three levels of district attorney recommendation, three of defense attorney recommendation, two levels of prior record, and two of local ties were coded, using the dummy variable technique suggested by Overall and Spiegel (1969). The results of this analysis are presented in Table 6. To determine the nature of the relationships between these four variables and the judges' final decisions, significance tests were performed using the logic of model comparison proposed by Applebaum and Cramer (1974). Briefly, this method tests the significance of the additional sum of squares that a particular factor can account for. To do this, the sum of squares accounted for by the most general model (in the present case, this was a model including all main effects plus the six two-way interactions between these four factors) is computed. Next, the sum of 
TAJBIE 6

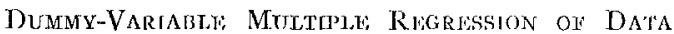
Selfcted from Explirimlint 2 to Match Values

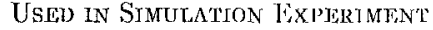

\begin{tabular}{|c|c|c|c|c|}
\hline Source & $S . S$ & $d f$ & $M S$ & $Y^{\prime}$ \\
\hline $\begin{array}{l}\text { Regression (all) } \\
\text { Regression (nain }\end{array}$ & 627.89 & 19 & 3.3 .05 & $3.84 * *$ \\
\hline only) & 530.91 & 6 & 88.49 & $10.28 * *$ \\
\hline $\begin{array}{l}\text { Residual (interetction) } \\
\text { Additional }\end{array}$ & 96.99 & 13 & 7.46 & $<1$ \\
\hline Loctl ties $(\Lambda)$ & 31.55 & 1 & 31.55 & $3.60^{* *}$ \\
\hline $\begin{array}{l}\text { Prior record (B) } \\
\text { Defense attorney }\end{array}$ & 8.12 & ] & 8.12 & \\
\hline $\begin{array}{l}\text { Defense attorney } \\
\text { (C) } \\
\text { District attorney }\end{array}$ & 48.88 & 2 & 24.44 & $2.81 \%$ \\
\hline $\begin{array}{l}\Lambda \times(B) \\
\Lambda \times C \\
\Lambda \times 1) \\
B \times C \\
B \times D \\
C \times Y\end{array}$ & $\begin{array}{r}308.36 \\
3.54 \\
27.58 \\
29.88 \\
2.48 \\
1.26 \\
4.5 .04\end{array}$ & $\begin{array}{l}2 \\
1 \\
2 \\
2 \\
2 \\
2 \\
4\end{array}$ & $\begin{array}{r}154.18 \\
3.54 \\
13.79 \\
14.94 \\
1.24 \\
.63 \\
11.26\end{array}$ & $\begin{array}{l}17.91^{*+\cdots} \\
<1.60 \\
1.74 \\
<1 \\
<1 \\
1.31\end{array}$ \\
\hline $\begin{array}{l}\text { Error } \\
\text { Regression (all main eflects }\end{array}$ & 370.23 & 43 & 8.61 & \\
\hline $\begin{array}{l}\text { Regression (all main eflects } \\
\text { including crime) } \\
\text { Additional due to severity }\end{array}$ & 533.04 & & & \\
\hline of crime & 2.13 & 2 & 1.07 & $<1$ \\
\hline
\end{tabular}

$* p<.10$

squares accounted for by a model excluding all of the two-way interactions is found. The difference between these two sums of squares represents the variance that all of the interactions can account for over and above that already handled by the four main effects. In Table 6 , this value is the residual in row 3 . An $F$ test of this term was far from significant, indicating that the interactions taken together did not account for additional variance. The additional sum of squares that each interaction separately accounted for was also computed. As can be seen, none of them approached acceptable significance levels. These results are in agreement with those from the simulation.

Table 7 contains the estimates of amount of bail derived from the results of the dummy-variable multiple regression analysis. Fach value represents the amount of bail that was predicted by the resultant regression equation (cf. Overall \& Spiegel, 1969). Comparison of thesc values with those in Table 1 makes the differences between the results of the two studies quite apparent. As can be seen, within the range of values studied there was virtually no effect of local ties nor of prior record on real bail-setting decisions, whereas both of these variables had significant effects on simulated decisions. In addition, the effects of district attomeys' recom- mendations were much larger in the latter than in the former case. Finally, the defense attorneys' recommendations had no effect in either instance. These conclusions are supported by the results of the sum of squares analysis in Table 6 . The additional amounts of variance that each of the four factors contributed to the main effect sum of squares are presented in rows 4--7. Only the main effect for the district attorney's recommendation was significant.

As an aid to the interpretation of the results from the above dummy-variable rcgression, another regression was perfomed that included the severity of the crime as a fifth factor. Only the main effects of these variables could be examined because of the singularity requirement in multiple rcgression. The severity of crime was divided into three levels, since not all of the original categories were represented in this selected data sample. The low severity level consisted of categories $f$ and $g$, the moderate level of categories $d$ and $e$, and the high level of category c. As can be scen in the bottom of Table 6, the addition of this variable added nothing to the predictive utility of the multiple regression. This result puts the comparison of the two experiments on firmer ground, since the simulation held severity of crime constant.

Overall, the comparative analyses lead to several conclusions about the difference between the controlled simulation and the actual bail-setting process. Within the range of values used, the simulation study indicated that the judges combined three types of information-prior record, local ties, and district attorneys' recommendation- in a noninteractive fashion. The present dummyvariable analysis yielded a somewhat different pattern of results, however. Instead of combining three types of information, the judges seem to have responded almost exclusively to the district attorney's recommendation. In fact, the district attorneys' recommendations accounted for almost all of the predictable variance in the judges' actual decisions: residual $F(3,43)=3.10, p<.05$, whereas the identical range of district attorney recommendations left much predictable variance unaccounted for in the simulation: residual $F(4,43)=7.52, p<.0005$. 
IABLE 7

Listumated Mean Bail, Set hy Jujges Computed from Dummy-Variable. MULILJ', REGRESSTON OF SELECTED DATA

\begin{tabular}{|c|c|c|c|c|c|c|c|}
\hline \multirow{4}{*}{$\begin{array}{l}\text { District } \\
\text { attormey rec- } \\
\text { ommendation }\end{array}$} & \multirow{4}{*}{$\begin{array}{l}\text { Prior } \\
\text { record }\end{array}$} & \multicolumn{6}{|c|}{ Defense attorney recommendation } \\
\hline & & \multicolumn{2}{|c|}{$\$ 0$} & \multicolumn{2}{|c|}{$\$ 550$} & \multicolumn{2}{|c|}{$\$ 1,100$} \\
\hline & & & & Strengt & ocal ties & & \\
\hline & & Strotig & Weak & Strong & Weak & Strong & Weak \\
\hline \multirow{2}{*}{$\$ 1,600$} & No & 597 & 1,140 & 1,321 & 830 & 1,597 & 1,184 \\
\hline & Yes & 743 & 880 & 1,854 & 957 & 1,712 & 1,371 \\
\hline \multirow{2}{*}{$\$ 2,250$} & No & 1,456 & 2,835 & 680 & 1,028 & 2,353 & 2,779 \\
\hline & Yes & 1,324 & 2,318 & 953 & 895 & 2,209 & 2,228 \\
\hline \multirow{2}{*}{$\$ 6,250$} & No & 2,761 & 4,899 & 2,500 & 3,604 & 3,013 & 4,194 \\
\hline & Yes & 2,798 & 4,529 & 2,906 & 3,604 & 3,001 & 3,776 \\
\hline
\end{tabular}

Note. Values are in clollars.

Several commonalities also emerged. The defense attorney recommendations played a very small role in both sets of data. Apparently, low defense attorneys' recommendations are, for all practical purposes, ignored by the judges. All of the two-way interactions in both sets of data were nonsignificant. Whatever the rule judges use to decide the amount of bail when the crime is not very severe and the defense attorneys' recommendations are low, that rule is not an interactive one.

\section{Generat Discussion}

The results of both studies lead to more general conclusions about the relative utility of using controlled laboratory research versus naturalistic observation to answer both theoretical and applied questions. Had we stopped with the simulation study, we would have concluded that judges take into account local ties, prior record, and district attorneys' recommendations, that local ties seem to be the most important, and that these three types of information are combined in a noninteractive manner. At a more general level, we would also have made a claim that a weighted averaging model with orthogonal weights could adequately account for the results. In contrast, in real bail hearings involving all cases except murders, prior record had little influence on the judges decisions, the district at- torneys' recommendations seemed to be the most important variable in the decision process, the defense attorneys' recommendations sometimes played a role in the decisions, and severity of the crime and local ties indirectly influenced the judges by controlling the district attorneys' recommendations. In addition, several types of information seemed to be combined in an interactive manner.

In short, there were a number of important differences between the two sets of data. After the fact, some, but not all of these differences, can be explained by assuming that low defense attorneys' recommendations, usually for minor felony crimes, are more or less ignored by the judges. This assumption can account for the lack of defense attorney effects in both the simulation and the dummy-variable regression analysis as well as its main effect in the full regression analysis. In conjunction with the weighted averaging model, it can also be used to explain the two interactions with defense attorneys' recommendations found in the naturalistic data. However, to do so requires that the weights and scale values be confounded in the naturalistic decision process, and this assumption could not have been reached from the simulation study alone.

The fact that different averaging models were required to explain the naturalistic and the simulation data (excluding the homicide cases) points out a problem inherent in gen- 
eralizing the results of controlled laboratory research to naturalistic settings. The effects produced by the range of values manipulated in a laboratory experiment may not be representative of the effects that the independent variables have over their entire range. In the present reseatch, it happend that the range of defense attorney recommendations used in the simulation were apparently within the range of defense recommendations usually ignored by judges in actual bail hearings. This fact would not have emerged had the naturalistic study not been conducted.

Several additional findings exemplify other problems that are likely to be encountered when laboratory simulations are used to draw conclusions about decision processes in the real world. The difference in the relative importance of local ties and the district attorney's recommendation is one such case. The effects on judges of these variables in the presence of a potentially critical nember of the "public," external to the legal system, were quite different from those reflected in the judges' actual court dlecisions. Such differences argue strongly for the use of naturalistic observation to justify claims about the generality of laboratory findings. Had naturalistic data not been collected, it would have been incorrectly concluded, on the basis of the simulation alone, that the judges were behaving in accord with the Vera Foundation plan by responding to the strength of local ties of the accused. In fact, only the district attorneys took local ties into account.

Paradoxically, the district attorneys recommended higher amounts of bail for four out of five categories of crimes when the accused had strong and moderate local ties than when he had weak ones. Since the judges' overwhelming reliance on district attorneys and their tendency to ignore or give low weights to redundant information in actual bail hearings have also been shown, it follows that in reality the judges behaved in a manner directly opposite to the Vera plan.

Because both the simulation and the naturalistic studies were conducted, it is possible in the present case to develop a reasonable picture of the decision process used by the average felony court judge. The major findings can be interpreted by assuming that both the judges and the district attorneys averaged information to arrive at their decisions. The judges averaged severity of the crime and the district attorneys' and the defense attorneys' recommendations in such a way that low defense recommendations were ignored or received a low weight. The district attorneys gave their recommendations by averaging severity of the crime and local ties in such a way that differences in severity of the crime were ignored when the local ties were weak. Although there is no way to directly test the goodness of fit of these integration models to the present data, they do offer a coherent and intuitively reasonable interpretation of felony court judges' bail-setting decisions.

From an applied point of view, the results of the present research portray a rather unfortunate picture of the way bail gets set in the San Diego (and possibly many other) felony courts. Even though a hearing is held in which both attorneys make a major point of discussing the prior record and local ties of the accused, the judges set bail in almost complete accord with the district attorneys' recommendations. This decision strategy seems inconsistent with the traditional claim that the accused is presumed innocent until proven guilty, especially since in the adversary system the district attorney's goal is to prove that the accused is guilty. If an accused person were innocent, responding to the recommendation of the district attorney would be extremcly unjust. Furthermore, since the district attorneys always seem to recommend a higher bail than the defense attorneys, following the former's recommendations is more likely to lead to discrimination against the poor. Finally, as already noted, the paradoxical tendency for the district attorney to recommend higher bail for most crimes when a person is strongly rather than weakly lied to the area is directly opposite to the highly praised Vera Foundation system.

Bail setting seems to be a fertile ground for future research directed at finding constructive alternatives to the current legal procedures. The differences found between the simulation and the naturalistic studies suggest that simulation and controlled laboratory research may be an inappropriate way to do such research. 


\section{REFERENCE NO'TE}

1. Anderson, N. H. Algebraic models for information integration. Technical Report No. 45, Center for Human Information Processing, University of California, San Diego, 1974.

\section{REFERENCES}

Anderson, N. H. Integration theory and attitude change. Psychological Reviev, 1971, 78, 171-206.

Anderson, N. H. Information integration theory: A brief survey. In D. H. Krantz, R. C. Atkinson, R. D. Luce, \& P. Suppes (Eds.), Contemporary developments in mathematical psychology (Vol. 2). San Francisco: W. H. Freeman, 1974.

Applebaum, M. I., \& Cramer, E. M. Some problems in the nonorthognal analysis of variance. Psychological Bulletin, 1974, 81, 335-343.

Birnbaum, M. $\mathrm{H}$. The devil rides again: Correlation as an index of fit. Psychological Bulletin, 1973, 79, 239-242.

Cohen, J. Multiple regression as a gencral dataanalytic system. Psychological Bulletin, 1968, 70, 426-443.
Coombs, C. H. Thurstone's measurement of social values revisited forty years later. Journal of Personality and Social Psychology, 1967, 6, 85-91.

Goldfarb, R. I. Ransom. New York: Harper \& Row, 1965.

Leon, M., Oden, G. C., \& Anderson, N. H. Functional measurement of social values. Journal of Personality and Social Psychology, 1973, 27, 301310.

Oden, G. C., \& Anderson, N. H. Differential weighting in integration theory. Journal of Experimental Psychology, 1971, 89, 152-161.

Overall, J. E., \& Spiegel, D. K. Concerning least squares analysis of experimental data. Psychological Bulletin, 1969, 72, 311-322.

Wildhorn, S., \& Greenwood, R. Unequal justice for all: An examination of felony defendants in Tos Angeles County. Psychology Today, August 1973, 14-16.

Wolf, G., \& Cartwright, B. Rules for coding dummy variables in multiple regression. Psychological Bulletin, 1974, 81, 173-179.

(Received August 19, 1974) 